\title{
ЭФФЕКТИВНЫЕ ПРИЁМЫ ОБУЧЕНИЯ РУССКОМУ ЯЗЫКУ КАК ИНОСТРАННОМУ, ИСПОЛЬЗУЕМЫЕ В ИНТЕРНЕТ-СРЕДЕ (НА ОСНОВЕ ТЕКСТОВ ПУБЛИЦИСТИКИ)
}

\section{EFFECTIVE METHODS OF TEACHING RUSSIAN AS A FOREIGN LANGUAGE USED IN THE INTERNET ENVIRONMENT (BASED ON PUBLIC TEXTS)}

Yang Xuejiao

Summary: The study of the possibilities of using the Internet environment is relevant due to the changed realities of modern education, where the emphasis is on interactivity and multimedia. Possessing a high didactic potential, journalistic articles published on the websites of journals can become the basis for organizing effective work aimed at solving educational problems. As part of the course Russian as a foreign language, it will be appropriate to use thematic online journals dedicated to the history and culture of Russia and its citizens. The effective methods of organizing work with an online article included verbal, visual, problembased learning methods.

Keywords: Russian as a foreign language, Internet environment, methods of teaching a foreign language, teaching methods, interactivity.
$\mathrm{B}$ современном образовательном пространстве отмечается тенденция использования мультимедийных, виртуальных средств обучения, которые обладая высоким дидактическим потенциалом, способствуют скорейшему и эффективному достижению целей иноязычного образования. На сегодняшний день значительное внимание уделяется обучению русскому языку, поскольку в последние годы его позиция в качестве международного средства общения укрепляется, что подтверждается фактом его включения в состав официальных языков $\mathrm{OOH}$ (Организация объединенных наций) [1].

Обозначим, что согласно новым стандартам образования основной целью высшего образования является формирование универсальной компетенции и общепрофессиональной компетенции. Применительно к дисциплине «Иностранный язык» данные компетенции достигаются за счет формирования у студентов-бакалавров умения осуществлять коммуникацию средствами иностранного языка в профессиональной деятельности [2].

Если ранее ФГОС (Федеральный государственный образовательный стандарт) ставил приоритет на формирование коммуникативной компетенции, под которой понимается умение осуществлять межличностную

\author{
Ян Сюецзяо \\ Аспирант, Московский педагогический государственный \\ университет, Москва \\ yanayang0218@gmail.com
}

Аннотация: Изучение возможностей применения интернет-среды актуально в силу изменившихся реалий современного образования, где акцент делается на интерактивность и мультимедийность. Обладая высоким дидактическим потенциалом, публицистические статьи, опубликованные на сайтах журналов, могут стать основой для организации эффективной работы, направленной на решение образовательных задач. В рамках прохождения курса РКИ уместно будет использование тематических онлайн-журналов, посвященных вопросам истории и культуры России и ее граждан. Кэффективным приёмам организации работы с онлайн-статьей были отнесены словесные, наглядные, приёмы проблемного обучения.

Ключевые слова: РКИ, интернет-среда, методика преподавания иностранного языка, приёмы обучения, интерактивность.

коммуникацию средствами изучаемого иностранного языка в различных речевых ситуациях по произвольным темам, то на сегодняшний день стоит задача формирования у студентов, проходящих обучение по курсу РКИ (Русский как иностранный), универсальных компетенций и общепрофессиональных компетенций [2].

Изучение зарубежной методической литературы, в частности работ таких авторов, как К.М. Армстронг (K.M. Armstrong) [3], Р. Блейк (R. Blake) [4], T. Кононелос (T. Cononelos) [6] и др. [4; 5], которые занимались вопросами применения Интернет-ресурсов в обучении иностранным языкам, показало, что методисты едины во мнении, что интернет-среда обладает высоким дидактическим потенциалом, в частности, она обеспечивает непрерывный доступ к аутентичной информации, погружение в языковую среду, что благоприятно сказывается на успеваемости студентов по предмету РКИ.

Проиллюстрируем возможности использования интернет-среды на занятиях РКИ в иностранной аудитории на примере текстов публицистики.

Прежде всего, отметим, что уместно будет использование тематических публицистических источников, 
которые освещают вопросы исторического и культурного развития России, что позволит сконцентрировать внимание исключительно на культуре страны изучаемого языка. К их числу можно отнести, например, онлайнжурнал «Моя Россия» (moiarussia.ru). Это не новостной, а познавательный проект, где представлены следующие рубрики: «История», «Факты», «Лица», «Города», «Мнения», «Традиции», «Места», «Природа» и др. Во всех перечисленных разделах основное внимание сконцентрировано на культуре, истории и уникальных чертах России и русского народа, что делает целесообразным применение данных публицистических статей на занятиях в рамках курса РКИ.

Отличительной особенностью приёмов обучения, используемых в интернет-среде, является их интерактивность и мультимедийность [6, с. 10], что способно поддерживать высокий уровень заинтересованности и концентрации студентов. Так, например, в журнале «Моя Россия» все статьи сопровождаются иллюстрациями, которые дают наглядное представление об обсуждаемом объекте, что повышает познавательный интерес. К примеру, статья «Рейтинг лучших городов России для проживания», опубликованная в рубрике «Города» (https://moiarussia.ru/rejting-luchshih-gorodov-rossii-dlyaprozhivaniya/) содержит перечень городов с описанием их лучших сторон и с фотографиями наиболее красочных мест. При работе с текстом такого рода целесообразно использовать различные приёмы, выделяемые современными методистами. Неограниченность информационного объема, представленного в интернет-среде, даёт возможность использования как словесных, так и наглядных, приёмов, а также приёмов проблемного обучения. На примере вышеуказанной статьи «Рейтинг лучших городов России для проживания» опишем особенности использования каждого приёма.

Специфика реализация словесного метода обуславливается способом трансляции самого текста, используемого в учебной деятельности - это публицистическая статья, размещенная на сайте журнала. В виду этого, для проведения аудиторной работы преподавателю необходимо заранее позаботиться о том, чтобы у студентов был доступ к тексту - либо распечатать публикацию заранее, либо проследить, чтобы учебная комната была оборудована компьютерами либо планшетами. После прочтения статьи можно предложить следующие упражнения: резюмирование (краткое изложение основных мыслей прочитанного), аннотирование, рецензирование, составление плана текста, пр. В случае, если сту- денты работают в классе, оснащённым компьютерами, вести подобную работу целесообразно в текстовом редакторе, где имеет возможность снабжения редактируемого текста гиперссылками, а также его рубрикацией и структуризацией, что позволит многогранно обработать прочитанную публицистическую статью с точки зрения ее информационной интерпретации.

Наглядный приём обучения реализуется за счет того, что публицистическая онлайн-статья снабжена красочными, привлекательными иллюстрациями, что, с одной стороны, повышает читательский интерес, а с другой, обеспечивает визуальное усвоение студентами архитектуры городов России, что способствует формированию культурной компетенции.

Что касается проблемного обучения, то на основе рассматриваемой статьи можно предложить самые разнообразные упражнения. Эффективным приёмом на пути реализации задачи по формированию критического мышления будет организация дискуссии или полемики, где центральными вопросами могут следующие:

Почему россияне предпочитают путешествовать по миру, а не по России? В каком городе России Вы хотели бы жить и почему? Как Вы считаете, миграционные потоки в тот или иной город - это явление позитивное или негативное.

Помимо этого, на основе публицистической статьи, размещенной в интернет-среде, целесообразным будет организовать среди студентов проектную деятельность, которая позволит внести вклад в развитие у обучающихся умений самостоятельного поиска и систематизации информации, критического осмысления проблемного вопроса, аргументации и тезисного изложения обработанной информации. На основе статьи «Рейтинг лучших городов России для проживания» может быть организован проект с названием «Топ-городов моей страны», в рамках которого студенты презентуют лучшие города своей страны и продемонстрируют их привлекательные стороны. Такая организация работы будет способствовать организации межкультурного взаимодействия.

\section{Выво $\Delta ы$}

К эффективным приёмам обучения русскому языку как иностранному, используемым в интернет-среде, рассмотренным в данной статье на примере публицистических текстов, были отнесены: словесные, наглядные и приёмы проблемного обучения.

\section{ЛИТЕРАТУРА}

1. Официальные языки ОOH. URL: https://www.un.org/ru/our-work/official-languages, дата обращения 02.10.2021.

2. Федеральные государственные образовательные стандарты. URL: https://fgos.ru/, дата обращения 01.10.2021. 
3. Armstrong K.M., Yetter-Vassot, C. Transforming teaching through technology. Foreign Language Annals, 27(4), 2014. - Pp. 475-486.

4. Blake R. CALL and the language lab of the future. ADFL Bulletin, 18(2), 2016. - Pp. 25-29.

5. Chun D.M., Brandl, K.K. Beyond form-based drill and practice: Meaning- enhanced CALL on the Macintosh. Foreign Language Annals, 25(3), 2020. - Pp. 255-267.

6. Cononelos T., Oliva, M. Using computer networks to enhance foreign language/ culture education. Foreign Language Annals, 26(4), 2013. - Pp. 527-534.

○ Ян Сюецзяо (yanayang0218@gmail.com).

Журнал «Современная наука: актуальные проблемы теории и практики»

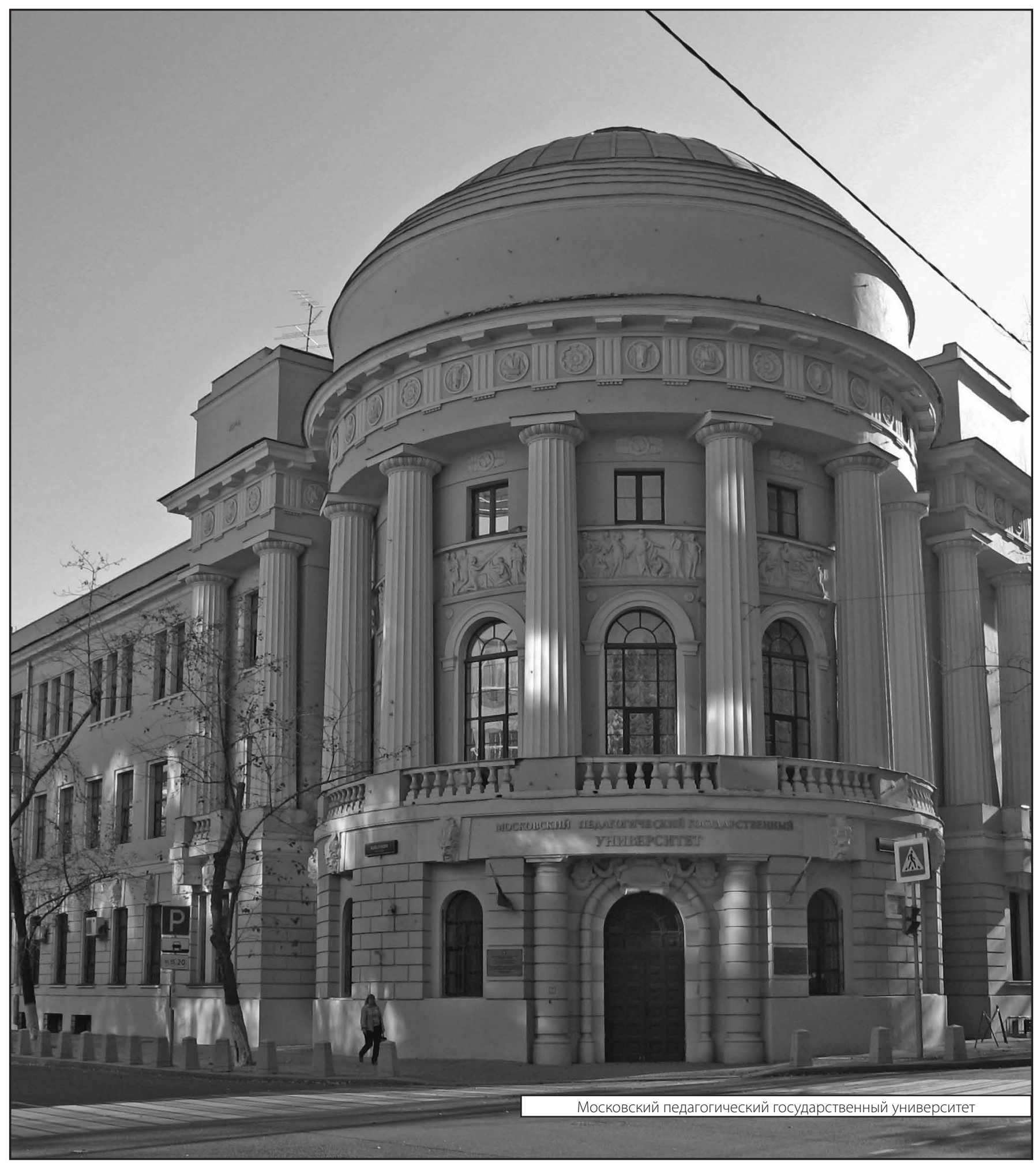

